QIJEI

International

Journal for

Educational Integrity

\section{How do faculty members respond to their students' discussions of academic misconduct and academic integrity?}

\author{
Lucia Zivcakova \\ Department of Psychology, Wilfrid Laurier University \\ dill2230@mylaurier.ca \\ Professor Eileen Wood \\ Department of Psychology, Wilfrid Laurier University \\ ewood@wlu.ca \\ Professor Mark Baetz \\ School of Business and Economics, Wilfrid Laurier University \\ mbaetz@wlu.ca \\ Domenica De Pasquale \\ Department of Psychology, Wilfrid Laurier University \\ depa7310@mylaurier.ca
}

Author's Notes: All correspondence regarding this manuscript should be directed toward Dr. Eileen Wood, Department of Psychology, Wilfrid Laurier University, Waterloo, Ontario, Canada, N2L 3C5 or ewood@wlu.ca.

\section{Keywords:}

Academic integrity, cheating, discussion, faculty members, misconduct, students

\section{Abstract}

The present study conducted a qualitative analysis of faculty members' perceptions, beliefs and instructional concerns regarding academic integrity in their classrooms following their observation of their students engaged in a 45-minute interactive presentation on academic integrity. Overall, seven overarching themes and a series of sub-themes were identified including the following: comfort level and knowledge about academic integrity issues (for faculty and for students), impressions about the interactive presentation, student engagement in the presentations, learning outcomes for faculty, safeguards against misconduct, and issues, consequences and proposed solutions to concerns. Key findings within these themes suggest that faculty members perceived themselves to be confident in their own understanding of what constitutes academic integrity; however, there were inconsistencies regarding whether their students had the requisite knowledge to make appropriate decisions. Faculty members were surprised by the frank and engaged interactions of their students during the interactive presentations. Only half of the faculty found the presentation content enhanced their own current knowledge. Faculty identified several methods they use to safeguard against academic misconduct, and identified the importance of both faculty and the institution providing a consistent and clear model to promote

The International Journal for Educational Integrity is available online at: http://www.ojs.unisa.edu.au/journals/index.php/IJEI/ 
academic integrity in students. Discussion explores insights gained as a context for informing instructional practice.

Student academic misconduct is broadly defined as any transgression which allows a student to gain an unfair advantage over his/ her peers and which results in an erroneous evaluation of the student (Davis, Drinan, \& Bertram Gallant, 2009). Much of the extant research on academic misconduct has focused on students to determine whether they engage in academic misconduct, how much they engage in misconduct, and individual or contextual variables, which may predispose students to engage in misconduct, or which may act as a protective factor against academic misconduct (Allmon, Page, \& Roberts, 2000; Crown \& Spiller, 1998; Christensen Hughes \& McCabe, 2006; Elzubier \& Rizk, 2003; Kidwell \& Kent, 2008; Kisamore, Stone, \& Jawahar, 2007). In addition, a substantial amount of the literature involves identifying forms of academic misconduct and the prevalence of these forms of misconduct (e.g., Christensen Hughes \& McCabe, 2006; Kidwell \& Kent, 2008; McCabe, 1993). Finally, a smaller set of research studies examines instructional or institutional mechanisms, which could reduce or prevent student academic misconduct, and promote academic integrity (e.g., Bean \& Bernardi, 2005; Boehm, Justice, \& Weeks, 2009; Sims, 2004; Soto, Anand, \& McGee, 2004). While each of these avenues is critical for understanding student academic misconduct, there is much less emphasis in the literature regarding the faculty and their experiences, perceptions, and practices about academic integrity. Given that faculty are charged with the responsibility of devising pedagogically appropriate instruction regarding academic misconduct in their classrooms, as well as typically being the first person to deal with students who have engaged in misconduct, it is important to understand faculty members' perspectives with respect to academic integrity and student academic misconduct. The present study investigated faculty members' perceptions regarding academic integrity issues.

Much of the existing research focusing on faculty and academic integrity examines relationships between students and faculty rather than faculty members' understanding or awareness of students' knowledge or attitudes regarding academic integrity issues (e.g., Laband \& Piette, 2000; Mason, Beardon, \& Davis Richardson, 1990; McKay, Kidwell, \& Kling, 2007; Tabachnick, Keith-Spiegel, \& Pope, 1991). For example, survey research has indicated that becoming sexually involved with a student, receiving sexual favors, money or gifts in exchange for grades, giving lower grades to students who strongly oppose your views, failure to acknowledge significant contributions from students in a publication, providing academic credit instead of financial remuneration for a student's work, ignoring a colleague's unethical behaviour, and including false or misleading information in a reference letter were all perceived to be unethical behaviours by faculty (Kidwell \& Kidwell, 2008; Laband \& Piette, 2000; McKay et al., 2007; Robie \& Keeping, 2004; Robie \& Kidwell, 2003; Tabachnick et al., 1991). Personal infractions also constituted significant breaches of misconduct, for example, manipulating, fabricating, or otherwise falsifying lab data (Laband \& Piette, 2000; McKay et al., 2007), and plagiarism (McKay et al., 2007). In general, these types of transgressions identified as serious transgressions by faculty, clearly have the potential to impact on the faculty-student relationship and could have direct impact on student performance outcomes. In addition, faculty members engaging in these types of behaviours provide poor role models, which may impart an implicit message that misconduct is acceptable, tolerated, and perhaps, normative (McCabe, 1993).

A second, less researched concern involves faculty members' understanding of academic misconduct within their classroom, and in particular, their awareness of what their students understand, believe, and do when it comes to academic integrity. Yet, this critical knowledge is a prerequisite for developing effective instruction about academic integrity in the classroom. Only a few studies have examined faculty perceptions of, and responses to student academic misconduct with many being specific to the issue of plagiarism. For example, Robinson-Zanartu, Pena, Cook- 
Morales, Pena, Afshani, and Nguyen (2005) examined faculty's perceptions regarding what constitutes plagiarism as well as their responses to student plagiarism.

Interestingly, faculty did not uniformly agree in their understanding of what constituted plagiarism. When faculty were presented with specific scenarios, which all involved plagiarism, faculty differed in their ability to detect the plagiarism. This outcome is consistent with Roig's (2001) results, who found that faculty often had difficulty making judgments about paraphrasing and summarising, thus making it difficult for some to judge what constituted plagiarism. Clearly, if faculty members have challenges defining plagiarism, they would be challenged in preparing appropriate instructional materials. Also, it would be likely that, unless uniform materials were provided, different faculty might present students with conflicting information.

Faculty members also differ in their preferences about how to deal with transgressions. For example, researchers (e.g., McCabe, 1993; Robinson-Zanartu et al., 2005) have found that faculty members often prefer to deal with instances of plagiarism on their own, and resort to official reports to the department only when the misconduct was judged to be very severe. Sanctions for transgressions also vary widely, and they tend to be very lenient (McKay et al., 2007; Robinson-Zanartu et al., 2005). In some cases, faculty members avoid enforcement of rules against academic misconduct both overtly and covertly. Overt failures occur when faculty observe, but do not confront students' cheating behaviour, while covert failures are present when faculty fail to discourage academic misconduct in the first place (McKay et al., 2007). As a result of inconsistencies, both across contexts and across faculty members, and the reluctance to pursue academic integrity issues, faculty have the potential to misdirect students' understanding of the importance of academic integrity and ethical conduct. How do students respond in these contexts? McCabe (1993) found that students' decisions to engage in misconduct are related to faculty behaviour. Specifically, when students heard that faculty were reluctant to deal with misconduct, with some ignoring it altogether, or giving slight sanctions, students selected courses taught by those faculty members, and these impressions from students were associated with increased rates of misconduct (McCabe, 1993). Findings such as these have prompted researchers and educators to define protocols and models for defining and responding to academic misconduct in higher education contexts (e.g., Sutherland-Smith, 2008).

Indeed, promoting academic integrity in the classroom has become an increasingly important topic in higher education. New initiatives have seen an increase in dedicated instructional time both within courses and group forums, such as orientation workshops (Bean \& Bernardi, 2005; Boehm et al., 2009; Sims, 2004; Soto et al., 2004). Some universities have dedicated resources, such as appointing an academic integrity officer or other staff, and designing protocols to ensure consistency in conduct. These resources have the potential to support and inform both faculty and students. In order to support faculty effectively, and to assist them in the construction of academically relevant materials for their classes, an understanding of faculty members' perceptions regarding their students understanding of academic integrity is needed.

\section{Summary of the present study}

The current study extended existing research on faculty members' perceptions of academic integrity. Rather than surveying faculty perceptions of ethics in an academic context in general, the study focused on faculty responses to their own students' participation in an interactive presentation on academic integrity. The materials and content were held constant across classes, which ensured that all faculty members would observe their students responding to the same issues about academic integrity, namely: what constitutes academic misconduct and students' experiences regarding misconduct, how misconduct is detected, consequences of misconduct, and perceptions regarding the importance of academic integrity. The faculty had the 
opportunity to hear directly from their students what the students understood as well as the students' experiences and explanations regarding ethical and unethical behaviour. Following observation of their class, faculty members were interviewed. This study is unique in providing faculty members with an opportunity to observe how their students responded to instruction about academic integrity, and how their students thought and felt about academic integrity.

\section{Method}

\section{Participants}

Initially, nine faculty members were approached by the University's academic integrity advisor, and they were asked whether they would be willing to participate in the study. All nine faculty members agreed to participate. The nine faculty members were responsible for teaching 15 courses. These courses represented one stream of studies that progressed from second to fourth year; however, each instructor only taught at one level (second-, third- or fourth-year), although some instructors taught more than one section at a particular level. Due to challenges in scheduling an interview time, one participant was not included in the final sample. The final sample therefore included eight faculty members (six males, two females) in the Business faculty at a mid-sized Canadian university. Four faculty members were lecturers (two part-time and two full-time), two held full-time contract positions, one was an associate professor, and one was an assistant professor. Overall, the faculty had a number of years of experience in their current University $(M=6.88, S D=6.15$ years), and they taught between one and eight courses $(M=3.13$ courses) in the year that the study was conducted. One faculty member taught second-year courses, four faculty members taught third-year courses and three faculty members taught fourthyear courses in the stream of courses.

\section{Materials and procedure}

Each faculty member observed his/her class engaged in an interactive academic integrity presentation, and they were all asked to participate in an interview after the sessions.

The topic of academic integrity was a curriculum expectation for each of the 15 classes in which the presentation was provided. Faculty members were approached by the University's academic integrity advisor prior to the beginning of term, and they were asked whether an interactive, discussion-based presentation on academic integrity presented by the academic integrity advisor could be used in lieu of one of their scheduled ethics classes for their course(s). Faculty members were provided with the full content of the presentation, including PowerPoint slides and the discussion prompts, and they had an opportunity to contribute comments and refinements to the materials. Suggestions were incorporated and approved by all instructors resulting in a scripted, 45-minute presentation, which was then given to each of the 15 classes. The presentation employed 26 PowerPoint slides to deliver content for four major topics on academic integrity: definition, detection, consequences of misconduct, and importance of academic integrity. Each of the four topics was introduced using quotations from previous students who had acted as ambassadors for academic integrity at the university. These quotations were followed by questions or prompts to encourage class members to share their knowledge and experiences. Faculty members were present throughout the presentation, and they were permitted to participate and/or observe, as they felt best worked for their class. 


\section{Interview}

Within three days of the interactive presentation each faculty member was contacted and participated in a one-on-one interview with a researcher. The interview consisted of 13 open-ended questions, and one seven-point Likert scale question. The 14 questions were:

1. What is your evaluation of how the discussion went in your class?

2. Were you surprised by any of the discussion that occurred during the class presentation?

3. Did you learn anything new from the session?

4. Has the session changed how you anticipate handling academic integrity discussions in your class?

5. How do you feel about discussing academic integrity in your class?

6. What safeguards do you build into your course to ensure/foster academic integrity?

7. How confident are you that your students read the syllabus?

8. On a seven-point scale, how comfortable are you that you know what constitutes academic integrity

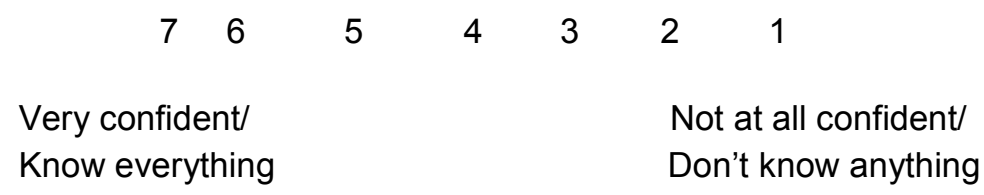

9. Where do students learn what defines academic misconduct?

10. Do you think your students know what academic misconduct is?

11. Did you notice any notable difference in the discussion across classes?

12. Have you ever had any issues in your classes with academic integrity?

13. What happened in your class after the presentation? Did it stimulate more discussion? Do you remember any specific statements from students that you found surprising?

14. Do you feel there is any other issue you would like to discuss?

All questions were asked in the same order across interviews. However, not all questions applied to each faculty member. For example "Did you see any noticeable differences between classes?" was only applicable for the five faculty who taught multiple classes that received the presentation. All faculty members were encouraged to elaborate on their responses when truncated responses were provided. Each interview was audio-taped for subsequent transcription and coding.

\section{Results and discussion}

All responses to the questions were transcribed verbatim. The transcripts were then analysed using an inductive coding technique (Strauss \& Corbin, 1990). As responses were read, emerging themes were identified and similar responses were then grouped under more abstract headings (Sahin, 2003). During this process, it was clear that common themes emerged across questions, therefore, the responses to all questions were read in their entirety, and where appropriate, shared information was aggregated across questions. All responses for all participants were captured by the resulting themes. To ensure reliability of the coding scheme, an explicit code of theme labels, definitions, and examples was developed (Boyatzis, 1998). Two raters used the coding scheme to code approximately $25 \%$ of the responses independently and had $85 \%$ agreement. Discrepancies were resolved through discussion (Boyatzis, 1998). 
In total, seven themes emerged. The themes could be grouped by focal point. For example, the first two themes were specific to faculty members regarding their own comfort and experience with academic integrity and their impressions regarding the presentation. The second grouping of themes (Themes 3 and 4 ) were specific to the faculty members' observations and understanding of student engagement and learning from the presentations. The final set of three themes dealt with instructional and pedagogical issues.

\section{1) Comfort level with academic integrity issues}

Question eight directly asked instructors to identify their own level of experience and comfort in dealing with academic integrity issues. Seven of the eight participants provided a numerical response and the resulting mean score $(M=5.86, S D=0.52)$ indicated that instructors were very comfortable with their understanding of what constitutes academic integrity. There was very little variability among instructors' ratings (range 5-6.5 out of 7). The one member who did not provide a numerical score indicated that a mark "on the lower side" would be appropriate. Faculty confidence in their ratings was explained through three subthemes: access to a knowledgeable peer; personal experience with academic misconduct process; and academic interest in the domain. Specifically, faculty members noted the knowledge and support that they had gained from having a fellow faculty member serving in the role of academic integrity advisor. Faculty members also discussed their experiences undergoing the process of making an allegation of misconduct against a student, and navigating through that process. This personal experience was clearly very salient, as one of the instructors acknowledged that his/her self-rating for knowledge and comfort in this area would have been "much lower the previous year" before going through the misconduct allegation process. In fact, among all of the participants, only one instructor had not been personally involved in an experience with academic misconduct in his/her class; however, even that instructor had identified the impact of exposure from observing the process that occurred in another section of the same course. Finally, one instructor identified personal experience through writing articles and books on the topic of academic integrity as a source of information and confidence in the rating.

Lower, and less than perfect ratings, were captured through one subtheme involving limited formal policy knowledge. This generally reflected a lack of awareness regarding the specific content or wording of the University's academic integrity policies. For example, the faculty member with the lowest ratings indicated that $s / h e$ had not read the policies.

Previous literature suggests that faculty may not be able to accurately assess what does and does not constitute academic misconduct in some cases (e.g., Roig, 2001). Yet, these faculty members were generally very confident in their knowledge and ability to recognise and assess academic integrity concerns with the one exception regarding the lack of familiarity with the wording in policy documents. This outcome is intriguing as it raises questions about the accuracy of faculty members' perceptions about their knowledge. Research supports a general tendency for individuals to overestimate their own abilities, resulting in an overconfidence effect (e.g., Pallier, Wilkinson, Danthiir, Kleitman, Knezevic, Stankov et al., 2002). Were the faculty members here accurate in their perceptions or overconfident?

It is possible that the outcome accurately depicts knowledgeable faculty members because these faculty members had an available, informative resource in the integrity advisor who was a member of their department. Research in other domains (Mueller, Wood, Willoughby, DeYoung, Ross, \& Specht, 2008) suggests that access to an available peer expert facilitates confidence, as well as skill and knowledge attainment. 
Faculty members' perceptions may also have been supported through their success in bringing academic misconduct cases through the formal channels. All but one instructor had hands-on experience going through the academic misconduct allegation process. Success in this process may further support perceptions regarding their ability to identify academic misconduct accurately, as the evidence of misconduct submitted by faculty was sufficient and accepted by the department. However, it may also be the case that faculty members chose to officially pursue only very clear-cut cases of misconduct, thus enhancing their perceptions of being highly knowledgeable about issues regarding academic integrity.

In the present study, it is hard to determine the accuracy of faculty members' perceptions. Future studies should include an objective assessment of knowledge regarding academic misconduct to accompany personal perceptions. Overall however, it is interesting that perceptions were as high as those reported, as this may have implications for interventions aimed at faculty members as well as their ability to provide instruction in this domain.

\section{2) Instructors' impressions about the presentations}

Although question one explicitly asked instructors about their perceptions of the presentation, this topic surfaced throughout the interviews. Two subthemes captured the instructors' impressions. First, all instructors responded to the presentation as a positive contribution to students' education; with the majority (five of eight) indicating that they found this format to be a "good basic idea", that it was "positive and worthwhile", and that they observed "interesting insights going on" among the students. However, this generally positive view was qualified by the second subtheme, which identified the short duration and one-time offering as insufficient. In fact, all instructors felt students needed more time, and/or more than one opportunity to discuss academic integrity in order to explore the issues raised in the presentation more fully, and to achieve sufficient depth to make the discussion most meaningful. For example, one instructor who observed two of his classes participating in the presentation summarised this concern in the following quotation:

In the first of the two sessions there was a very good comment made by one of the students about academic integrity and a lack thereof that started a bit of a discussion and I would really have liked the full session to go through that in more depth and to explore it a bit more their opinions and I think their learning would have been enhanced dramatically by having more time so they could actually think about it, talk about it a lot more. Yeah, my complaint is that it was too condensed.

Indeed, the need for more instructional time was evident when two faculty members reported that they continued the discussion with their class after the presentation was over. This extended discussion did not repeat presentation content or discussion, but instead yielded further insights regarding why students make choices to cheat, and included discussion beyond the academic sphere to subsequent ramifications that academic misconduct at university might have for students' future success in the workplace. This outcome is consistent with previous work that identified the need for students to be exposed to issues of academic integrity continuously (Dichtl, 2003).

Overall, the instructors' perceptions support incorporating explicit and interactive discussions of academic integrity in the classroom. However, the evaluations make clear that these presentations should not be a simple, one-shot consideration, but instead, need either repeated opportunities or extensive sessions to allow the topic 
the breadth and depth of discussion deemed optimal. Faculty comments are consistent with recent research where academic integrity advisors and administrative personnel are calling for consistency in the presentation and discussion of academic integrity, with clear, accurate presentation of rules and guidelines (Bean \& Bernardi, 2005; Bertram Gallant \& Drinan, 2008; Robinson-Zanartu et al., 2005).

\section{3) Perceptions of student involvement in presentation}

Perceptions about student engagement during the presentation, and more globally, about engagement with issues related to academic integrity were captured through two subthemes. The first subtheme involved selective engagement, and the second, quality or level of engagement. With respect to selective engagement, half of the faculty expressed concerns about the number of students who decided not to participate in the presentations. Although ethics was a required part of the course, attendance at the presentation in particular was made optional for students, in order to comply with guidelines of ethical conduct as set out by the Research Ethics Board. The faculty who expressed concern noted a significant portion of their classes left just prior to the presentation, or failed to attend the class. The level of absence was notable for these instructors through comments such as "The only thing I was a little concerned, there was a mass exodus before the presentation." or "We were using unfortunately only about half the class". Although the remaining instructors did not comment on absences, perhaps because selective attendance was not an issue for all classes, selective attendance was clearly a concern. If academic integrity is to be given a valid and important place within the university setting, allowing students the option to withdraw from presentations on the topic may not be suitable. However, understanding what encourages some students to attend and others to avoid such presentations would be a worthy topic of further investigation.

The majority of discussion regarding student responses to the presentation, however, involved the level of participation evident among those who attended. Instructors were clearly impressed by the level of participation from the students finding them very participative and commenting on how "good (it was) to see them take their time and listen". Clearly, students were paying attention and being involved. What surprised many faculty members was the honesty in the exchanges among students and with the presenter, even while they were in the room. Instructors were "impressed with how forthright (students) were," and described the students as being "surprisingly frank" and "forthcoming". Only one instructor found his/her class "not very forthcoming, they were holding back". These observations are very important as they indicate that the majority of students appeared willing to participate in an open discussion about academic integrity, and they were not afraid to raise 'thorny' or 'risky' issues even when they were raising these issues in the presence of their instructors. This insight was surprising to many instructors who had thought students would be reserved or hesitant, especially with them in the room.

Perhaps having the academic integrity advisor deliver the presentation gave the presentation the weight and credibility required to make students open and "frank". However, those who talked with students after the presentation indicated that the students in these discussions became "very involved" and "emotional". The emotional response was perceived as positive, because it indicated the intensity with which students experienced issues involving academic misconduct. These observations indicated that faculty members were not aware that their classes would engage in this level of honest, open, and sensitive discussions. However, faculty members were encouraged to see that this level of exchange was possible, and as some faculty members stated that their observations would impact their decision to engage their class in discussion rather than simply providing explicit instruction without discussion when introducing academic integrity issues. Overall, congruent with previous literature 
(Gynnild \& Gotschalk, 2008) a classroom discussion based on a presentation was found to be an effective forum for teaching and learning about academic integrity.

\section{4) Faculty perceptions about student's level of knowledge and perceptions about academic integrity}

Not surprisingly, faculty members' perceptions of student knowledge of academic integrity varied considerably. One subtheme captured the idea that most instructors indicated that students know what academic misconduct is. However, they differed in their conception of the depth and quality of such knowledge. To illustrate, several faculty members believed that students "know the expectations, but they do not necessarily know the calendar definition of academic misconduct". In fact, some faculty members expressed very strong opinions that students who come to University know exactly what misconduct is, that "(students) learn tacit knowledge, talking to their peers, who gets away with what, the 'rumour'". Similarly, instructors believed that students who engage in academic misconduct:

know that it is wrong because they get a 'twinge,' and if they get caught they are gonna get punished, and that the degree of punishment is gonna vary. And yes, (students) express surprise of 'where was it' (written in the calendar or course outline) and 'I didn't sign any contract', you know all of those excuses but inside they fully know what they've done and fully appreciate what they have been involved in and fully expect to get punished and are just trying to minimise the impact.

Nonetheless, some faculty members admitted that relying on rumour is a concern, as illustrated in the following quote: "The only problem is that it's a rumour mill that gets changed as it goes along".

Based on these results, an underlying contradiction becomes apparent. That is, faculty members indicated that they believed students know exactly what academic misconduct is, even when they also believe that students do not know the official definition of misconduct, and acknowledged that the knowledge that students do possess is often based on implicit learning and rumour that is often incorrect. This contradiction provides an opportunity for miscommunication. If faculty members believe that students know what academic integrity is, then they may not feel they have to review or present information on this topic. At the same time, however, if they believe that what students know may be inaccurate and incomplete, not presenting information could leave students vulnerable and open to errors in understanding. In order to avoid miscommunication and misunderstandings, it may be necessary to review, in some systematic way, the fundamentals of academic integrity in order to ensure common knowledge and expectations (Boehm et al., 2009; Christensen Hughes \& McCabe, 2006; McCabe, Trevino, \& Butterfield, 2001).

In contrast, there was concern that some students may opt to remain in the dark regarding academic integrity either due to lack of interest ("don't care to find it," even though it is widely available in the calendar or on the website), or as a strategic mechanism so that they cannot be held responsible for their behaviours if or when they are caught. Indeed, two instructors commented on responses from students who indicated that the students did not feel it was their responsibility to have knowledge about academic integrity. Faculty saw these comments as reflections of a peer culture where academic integrity is not perceived to be important, and where there is a decreased requirement for vigilance. In addition, the issue of entitlement was offered as an explanation for why students might not be concerned with transgressions with students feeling it is acceptable to cheat, because they are entitled to receive higher grades. 
A second subtheme offered an explanation for why students might not be aware of the penalties for academic misconduct. Specifically, instructors were hesitant to share this information with students. Instructors felt that they could not provide concrete examples to students, because the penalties were perceived to be inconsistent and too lenient, and making students aware of this would only give students a "go ahead" to cheat. Indeed, one instructor explained how the topic of concrete examples is avoided, exactly because faculty members do not want to let students know that penalties are light in the following quote:

When asked why don't (instructors) talk about concrete examples, (instructors) say its because of confidentiality, but really, the reason is that they would have to say the severity of penalties is going down in a mark, from $A+$ to a $B$.

A potential solution to concerns about students being misinformed, unaware, or intentionally uninformed was captured in a subtheme suggesting that there should be required instruction in the earliest days upon entry to the school. This theme was expressed by one instructor who stated:

I think at the point that we get them, we then have to provide the explanations (for) those that have limited integrity. Understand what misconduct means, what the consequences are, and I think that needs to happen at the beginning in a week. I really believe that it needs to kick off at the beginning. I don't care what happened at your high school, and I don't care what things you were able to get away with. You can't get away with it here. These are the rules and this is how we are going to enforce it. And then reinforce it through the years.

In contrast, there were also faculty members who believed that the University promoted academic integrity to the point where students hear too much about it; that they are "over-bombarded" with it. This was perceived as problematic, because students stop listening, and "block out" relevant information, which then "doesn't sink in". Given that students are potentially presented with the same information about academic integrity in each class, within the class syllabus, and in the calendar, it is indeed possible that they may become resistant to it. This finding suggests that students need to receive consistent but perhaps hierarchically organised discussionbased presentations that focus on concerns specific to the academic level and assignments. Such presentations would aid in increasing knowledge of academic integrity issues more effectively, and without significant repetition.

\section{5) Learning outcomes for faculty}

Although half of the instructors found that the classroom presentations did not provide them with new content knowledge, nonetheless all instructors found observing the sessions informative. Three subthemes captured what was learned by faculty; review, content knowledge, and personal insights. Having an opportunity to review academic integrity policy was cited as an important outcome for half of the instructors. Three instructors indicated that they acquired new content knowledge. Another two instructors indicated that the exchanges from students provided them with insights. In particular, they were surprised to see the students' interest in concrete examples. All of the instructors indicated that having observed their students in the presentations would influence their teaching practice. For some, the instructional approach was most salient, as they indicated that they would adopt a discussion-based approach in the future to encourage talking and sharing of views, and to promote greater critical thinking about the issues. 
Personal insights were reported with respect to instructors' level of awareness about the prevalence of academic misconduct in their unit. Although instructors stated that they believed that some of their students engaged in academic misconduct, the majority of faculty expressed surprise at how many students put up their hand when asked whether anybody had ever observed cheating. Although faculty members were surprised by the number of students reporting seeing cheating occur, this outcome is consistent with existing research that reports similarly high levels of academic misconduct (Kidwell \& Kent, 2008, McCabe et al., 2001). Instructors were also surprised and disappointed at how reluctant students were to report observed cheating. In addition, two instructors were surprised at students' lack of awareness that grades are "locked in a normal bell curve" and that when students observe cheating but fail to report it, they may be allowing other students to take the few available As, therefore limiting their own chances of achieving such grades.

\section{6) Safeguards against misconduct}

Across all of the faculty members, the safeguards used to prevent or reduce academic misconduct could be grouped into four subthemes: various uses of textmatching detection software, consistency, general control procedures, and discussion.

a) Text-matching software: Half of the faculty members indicated that they use textmatching software to detect cases of plagiarism, specifically, Turnitin. This web-based software compares written work to all other essays and internet-based material submitted to the same website. Two of these four faculty members indicated that they prefer to use Turnitin as a learning tool, rather than solely as a tool for detecting plagiarism. The following quote describes this alternate use of Turnitin more precisely:

I allow students multiple submissions up to due date. I encourage them to actually use the report that they get to verify that they have cited correctly, where they might not have thought they did. I am not saying that they can adjust it but that they just cited correctly, because many students are confused, they see the percentage and they think that's wrong. They could have something that for a better term is plagiarised from a source but at least they have cited and identified that its from another source and they didn't try to pass it as their own work, I am ok with that. As long as it fits with their discussion of what they are trying to get across. So I try to use it as a tool as opposed to a discipline.

Creatively using text-matching software as an instructional tool allows students to become aware of, and learn from their errors. This instructional use of Turnitin may be especially appropriate for introductory students who may be unaware of plagiarism, or who do not know how to paraphrase, summarise or source properly. However, clarification regarding correct citing and higher expectations of accuracy may be more appropriate use of the technology in higher grades.

b) Consistency: Four faculty members indicated that they make special effort to ensure consistency in the way they handle academic misconduct issues across students, and across sections of the same course. Similarly, effort was made to ensure parallel scheduling of all midterm, final, and make-up exams for all sections on the same day and time to avoid diffusion of information among students.

c) General control procedures: Instructors also listed a variety of general control procedures to minimise academic misconduct. Consistent with previous research (Boehm et al., 2009; McCabe et al., 2001), these procedures included using short 
essay questions rather than multiple-choice questions, choosing questions for an exam out of a question bank to ensure novelty in the questions presented over years/ sessions, using multiple versions of an exam, and employing good proctoring techniques. Others procedures included retaining assignments to minimise trading or selling old assignments, and posting student presentations online where they would be visible to everyone else, to avoid plagiarism. These preventative strategies aimed at avoiding or reducing instances of misconduct, while improving grading/evaluation techniques, are consistent with effective strategies that are highlighted in previous research (Gynnild \& Gotschalk, 2008).

d) Discussion: Two instructors mentioned that they realised the need for explicit discussion of expectations to clarify how student collaboration for brainstorming purposes differs from what appears in individual written assignments. They also noted the importance of giving students opportunities to ask questions when in doubt about what constitutes misconduct. Clarifying expectations and promoting open communication are critical foundations for reducing misconduct (Gynnild \& Gotschalk, 2008).

The suggestions provided by faculty resonate with findings from past research, and provide concrete examples that can be used to promote academic integrity, and decrease the levels of academic misconduct.

\section{7) Issues, consequences, and proposed solutions}

Instructors readily identified several issues that were a concern to them. All of the issues were captured by two subthemes: issues with other faculty members or more frequently, issues embedded within the institution.

Consistent with McCabe (1993), modeling of unethical behaviour by fellow faculty members was a significant concern. As one faculty member put it: "If we can't do that (act in an ethical manner) and set that role model, it is a lot to ask our students to be better than we are". Specifically, several types of unethical or ambiguous conduct by faculty members were identified in the interviews. Milder offences included re-using old exams and assignments as contributing to academic misconduct by allowing students to readily gain access to such materials. To qualify this statement, the faculty members also understood that other faculty members recycle old exams and assignments, because "people get rewarded for research, through merit, through recognition, whatever. There is very little reward for being a good teacher". More severe offences included not reporting academic misconduct officially, and teaching students that it is not necessary to submit an application, and receive approval from the University Ethics Board to conduct research on human participants. Consistent with previous research by Boehm et al. (2009), some faculty members noted that it might be worthwhile to "provide ethical training to all faculty," especially incoming faculty during events such as "instructor orientation" or "teaching day".

Congruent with previous research (de Lambert, Ellen, \& Taylor, 2006; Dichtl, 2003), several faculty members stated that some concerns about academic integrity are specific to the institution, in particular, the University's lack of consistent rules and guidelines, and lack of support for faculty members who are pursuing issues of academic misconduct. As a result of these perceived problems, some faculty members chose to deal with misconduct on their own. When dealing with misconduct on their own, the rationales included: personal beliefs that "everyone deserves a second chance," and "you don't want to see a fourth-year student fail just because they had bad judgment"; apathy or avoidance demonstrated through statements, such as "I did not want to be burdened with the paperwork", "It is not my responsibility if they don't learn anything"; and previous negative experience with academic misconduct, which "took a great deal of time on everyone's part. Hours and hours. 
That's not something I would want to repeat again. It was very frustrating". These outcomes coupled with the concern that "there are no universal guidelines among faculty" and "students receive different, confusing messages from faculty" reflected a great deal of frustration felt by the instructors.

Frustration could be minimised or avoided by having clear, consistent, hierarchically arranged systems for handling academic misconduct (Gynnild \& Gotschalk, 2008). However, such systems would also need to have some flexibility to give students an opportunity to learn from their mistakes. Instituting specific protocols and holding everyone accountable for executing them provides consistency, equality, and predictability, while avoiding concerns associated with lack of interest, apathy, and nonchalance (Gynnild \& Gotschalk, 2008).

Finally, it is also important to acknowledge that faculty members were not compensated for the extra time spent dealing with issues of academic misconduct, and students could threaten a lawsuit both against the institution as well as against the instructor personally. Faculty need to see that academic integrity is important at the highest levels of the institution to warrant their efforts. In addition, support for faculty both from administration and peers might facilitate more effective and efficient handling of academic integrity issues (Boehm et al., 2009).

\section{Closing comments}

Allowing faculty the opportunity to observe what happens when students are given an explicit interactive forum for discussion of academic integrity influenced these faculty members with respect to their perceptions about their students' needs, their institutional needs, and their own teaching practice. Faculty members reported finding this opportunity to watch their class engage in open discussion about academic integrity insightful.

One of the striking outcomes was the surprise faculty members' reported at hearing their students discuss academic integrity issues in frank, honest, and emotional ways. In fact, in some cases, faculty members prompted by this observation extended the discussion, or re-initiated it in subsequent classes. Knowing that students are willing to engage in discussion, and in fact, want to engage in discussion, provides substance to efforts to actively engage students in areas of academic integrity (Dichtl, 2003).

For many faculty members the interactive format was perceived to be more effective and engaging than more traditional direct instruction approaches. Interestingly, some faculty members found that they gained content knowledge from attending the presentations, while others gained a greater understanding of their students' needs for particular content information. Specifically, student requests for concrete examples were noted, and faculty indicated that these insights would inform the content they provided in future instruction. In summary, both the form and the content of these presentations yielded important insights for faculty members, and provided direction for future instructional practice.

The interviews also yielded concerns at a higher administrative level. Many of the issues cited by faculty stem from the institutions' lack of official rules, regulations, and guidelines to deal with issues of academic integrity. Even though these faculty members had access to an academic integrity advisor, and acknowledged benefiting from that available expertise, more resources dedicated to supporting academic integrity, and in particular, training faculty and students, were suggested. 
Support systems, however, will need to scaffold both the conceptual understanding of academic integrity, and the practical skills that will allow students and faculty to execute the behaviours that are required. In the present study, faculty members' perceived knowledge was high but there was no mechanism for assessing actual knowledge. Ensuring that perceived levels of knowledge are matched with actual skills is necessary. Future research will need to concentrate on mechanisms that will bring perceived levels of knowledge into alignment with actual knowledge.

Although faculty here believed that their students had an understanding of what constituted academic misconduct, there was sufficient concern that students were equipped with ill-found or poorly articulated knowledge. This clearly shows the need for clear, explicit instruction, as well as the opportunity for students to ask questions, and engage in discussion about academic integrity.

Forums where faculty have the opportunity to learn first-hand from their students, such as in the present study, might be useful in the construction of academic integrity support systems to ensure that faculty perceptions become an integrated part of future protocols and recommendations.

\section{References}

Allmon, D. E., Page, D., \& Roberts, R. (2000). Determinants of perceptions of cheating: Ethical orientation, personality and demographics. Journal of Business Ethics, 23, 411-422.

Bean, D. F., \& Bernardi, R. A. (2005). Accounting ethics courses: A professional necessity. The CPA Journal, 75(12), 64-65.

Bertram Gallant, T., \& Drinan, P. (2008). Toward a model of academic integrity institutionalization: Informing practice in postsecondary education. The Canadian Journal of Higher Education, 38(2), 25-44.

Boyatzis, R. (1998). Transforming qualitative information: Thematic analysis and code development. Thousand Oaks, CA: Sage.

Boehm, P. J., Justice, M., \& Weeks, S. (2009). Promoting academic integrity in a higher education context. The Community College Enterprise, 15(1), 45-61.

Christensen Hughes, J. M., \& McCabe, D. L. (2006). Academic misconduct within higher education in Canada. The Canadian Journal of Higher Education 36(2), $1-21$.

Crown, D. F., \& Spiller, M. S. (1998). Learning from the literature on collegiate cheating: A review of empirical research. Journal of Business Ethics, 17(6), 683 -700 .

Davis, S., Drinan, P., \& Bertram Gallant, T. (2009). Cheating in school: What we know and what we can do. Malden, MA: Wiley-Blackwell.

de Lambert, K., Ellen, N., \& Taylor, L. (2006). Chalkface challenges: A study of academic dishonesty amongst students in New Zealand tertiary institutions. Assessment and Evaluation in Higher Education, 31(5), 485-503.

Dichtl, J. (2003). Teaching integrity. The History Teacher, 36(3), 367-373.

Elzubier, M. A., \& Rizk, D. E. (2003). Exploring perceptions and attitudes of senior medical students and interns on academic integrity. Medical Education, 37, 389 -396 .

Gynnild, V., \& Gotschalk, P. (2008). Promoting academic integrity at a Midwestern university: Critical review and current challenges. The International Journal for Educational Integrity, 4(2), 41-59.

Kidwell, L. A., \& Kent, J. (2008). Integrity at a distance: A study of academic misconduct among university students on and off campus. Accounting Education: An International Journal, 17, S3-S16. 
Kidwell, L. A., \& Kidwell, R. E. (2008). Do the numbers add up to different views? Perceptions of ethical faculty behaviour among faculty in quantitative vs. qualitative disciplines. Journal of Business Ethics, 78, 141-151.

Kisamore, J. L., Stone, T. H., \& Jawahar, I. M. (2007). Academic integrity: The relationship between individual and situational factors on misconduct contemplation. Journal of Business Ethics, 75, 381-394.

Laband, D. N., \& Piette, M. J. (2000). Perceived conduct and professional ethics among college economics faculty. American Economist, 44(1), 24-33.

Mason, J. B., Bearden, W. O., \& Davis Richardson, L. (1990). Perceived conduct and professional ethic among marketing faculty. Journal of the Academy of Marketing Science, 18(3), 185-197.

McCabe, D. L. (1993). Faculty responses to academic dishonesty: Honour codes and other contextual influences. Research in Higher Education, 34, 647-658.

McCabe, D. L., Trevino, L. K., \& Butterfield, K. D. (2001). Cheating in academic institutions: A decade of research. Ethics \& Behavior, 11(3), 219-232.

McKay, R. B., Kidwell, L. A., \& Kling, J. A. (2007). Faculty ethics from the perspective of college of business administrators. Journal of Legal, Ethical and Regulatory Issues, 10(1), 105-124.

Mueller, J., Wood, E., Willoughby, T., DeYoung, T., Ross, C., \& Specht, J. (2008). Identifying discriminating variables between teachers who fully integrate computers and teachers with limited integration. Computers \& Education, 51, 1523-1537.

Pallier, G., Wilkinson, R., Danthiir, V., Kleitman, S., Knezevic, G., Stankov, L., \& Roberts, R. D. (2002). The role of individual differences in the accuracy of confidence judgments. The Journal of General Psychology, 129(3), 257-299. doi: 10.1080/00221300209602099

Robie, C., \& Keeping, L. M. (2004). Perceptions of ethical behaviour among business faculty in Canada. Journal of Academic Ethics, 2, 221-247.

Robie, C., \& Kidwell, R. E. (2003). The "ethical" professor and the undergraduate student: Current perceptions of moral behavior among business school faculty. Journal of Academic Ethics, 1, 153-173.

Robinson-Zanartu, C., Pena, E. D., Cook-Morales, V., Pena, A. M., Afshani, R., \& Nguyen, L. (2005). Academic crime and punishment: Faculty members' perceptions of and responses to plagiarism. School Psychology Quarterly, 20 (3), 318-337.

Roig, M. (2001). Plagiarism and paraphrasing criteria of college and university faculty. Ethics and Behavior, 11(3), 307-323.

Sahin, T. Y. (2003). Student teachers' perceptions of instructional technology: Developing materials based on a constructivist approach. British Journal of Educational Technology, 34, 67-74.

Sims, R. R. (2004). Business ethics teaching: Using conversational learning to build an effective classroom environment. Journal of Business Ethics, 49, 201-211.

Soto, J. G., Anand, S., \& McGee, E. (2004). Plagiarism avoidance: An empirical study examining teaching strategies. Journal of College Science Teaching, 33, 4248.

Strauss, A., \& Corbin, J. (1990). Basics of qualitative research: Grounded theory procedures ad techniques. Newbury Park, CA: Sage.

Sutherland-Smith, W. (2008). Plagiarism, the internet and student learning: Improving academic integrity. New York: Routledge.

Tabachnick, B. G., Keith-Spiegel, P., \& Pope, K. S. (1991). Ethics of teaching: Beliefs and behaviors of psychologists as educators. American Psychologist, 46, 506515. 


\section{About the authors}

Lucia Zivcakova is a $\mathrm{PhD}$ candidate in the Developmental Psychology program at Wilfrid Laurier University working under the supervision of Dr Eileen Wood.

Lucia Zivcakova examines the use of technology in learning. More specifically, her primary research focuses on multi-tasking using digital technologies on learning in a real-time classroom lecture. Her secondary research investigates the effectiveness of interventions aimed at improving academic integrity and other issues surrounding academic integrity.

Eileen Wood is a Professor in Developmental Psychology at Wilfrid Laurier University. She has written/edited 12 books, 7 manuals and over 65 refereed research publications with two books receiving a "Book of the Year" award. Dr Wood has received awards for research and teaching. Her research examines how children and adults acquire, retain and understand information presented through traditional text and digital media. In addition, she investigates social and cognitive outcomes in both formal (e.g., classrooms) and informal learning environments (e.g., gaming) and instructional supports that assist learning in these environments. She also examines issues related to academic integrity.

Mark Baetz was a Professor in the School of Business and Economics Wilfrid Laurier University. He taught undergraduate and graduate courses related to strategic management and corporate social responsibility. Dr Baetz has published several books and articles related to mission statements, consultation by government in the environmental sector, and ethical dilemmas in teaching. Most recently, he was the academic integrity advisor for the university and has conducted research in this domain.

Domenica De Pasquale is a PhD student studying developmental psychology at Wilfrid Laurier University. Her research interests include how children and adults learn independently and when working with others. 